\title{
Derived bedrock elevations, strain rates and stresses from measured surface elevations and velocities: Jakobshavns Isbræ, Greenland
}

\author{
JAMES L. FASTOOK, \\ Department of Computer Science, University of Maine, Orono, Maine 04469-5752, U.S.A. \\ HenRy H. BRECHER, \\ Byrd Polar Research Center, The Ohio State University, Columbus, Ohio 43210, U.S.A. \\ Terence J. Hughes \\ Institute of Quaternary Studies, University of Maine, Orono, Maine 04469-5752, U.S.A.
}

\begin{abstract}
Jakobshavns Isbra $\left(69^{\circ} 10^{\prime} \mathrm{N}, 49^{\circ} 59^{\prime} \mathrm{W}\right)$ drains about $6.5 \%$ of the Greenland ice sheet and is the fastest ice stream known. The Jakobshavns Isbræ basin of about $10000 \mathrm{~km}^{2}$ was mapped photogrammetrically from four sets of aerial photography, two taken in July 1985 and two in July 1986. Positions and elevations of several hundred natural features on the ice surface were determined for each epoch by photogrammetric block-aerial triangulation, and surface velocity vectors were computed from the positions. The two flights in 1985 yielded the best results and provided most common points (716) for velocity determinations and are therefore used in the modeling studies. The data from these irregularly spaced points were used to calculate ice elevations and velocity vectors at uniformly spaced grid points $3 \mathrm{~km}$ apart by interpolation. The field of surface strain rates was then calculated from these gridded data and used to compute the field of surface deviatoric stresses, using the flow law of ice, for rectilinear coordinates, $X, Y$ pointing eastward and northward, and curvilinear coordinates, $L, T$ pointing longitudinally and transversely to the changing ice-flow direction. Ice-surface elevations and slopes were then used to calculate ice thicknesses and the fraction of the ice velocity due to basal sliding. Our calculated ice thicknesses are in fair agreement with an ice-thickness map based on seismic sounding and supplied to us by K. Echelmeyer. Ice thicknesses were subtracted from measured ice-surface elevations to map bed topography. Our calculation shows that basal sliding is significant only in the $10-15 \mathrm{~km}$ before Jakobshavns Isbræ becomes afloat in Jakobshavns Isfjord.
\end{abstract}

\section{INTRODUCTION}

Jakobshavns Isbrx $\left(69^{\circ} 10^{\prime} \mathrm{N}, 49^{\circ} 59^{\prime} \mathrm{W}\right)$ is the fastest known ice stream, moving more than $7 \mathrm{~km} \mathrm{a}^{-1}$ at its calving front (Carbonnel and Bauer, 1968). It forms at the confluence of two ice streams, a short slow one from the north and a long fast one from the east. Its last $10 \mathrm{~km}$ becomes afloat in Jakobshavns Isfjord on the west coast of Greenland (Fig. 1). Figure 1 also shows less concentrated stream flow converging from the southeast. Jakobshavns Isbræ drains about $6.5 \%$ of the Greenland ice sheet (Bindschadler, 1984). Our photogrammetric survey was confined to the $10000 \mathrm{~km}^{2}$ area of strongly converging flow into Jakobshavns Isbræ, the area in Figure 1.

Although its calving front retreated about $27 \mathrm{~km}$ from 1850 to 1964, Jakobshavns Isbræ has been close to massbalance equilibrium since then (Pelto and others, 1989). Rapid retreat has been ascribed to climatic warming at the end of the "Little Ice Age". At this time surface melting increased considerably, with additional meltwater reaching the bed through crevasses and moulins. This enhanced lubrication increased the sliding velocity, which in turn accelerated crevasse formation and iceberg discharge, all in positive feed-back which we call the Jakobshavns effect.

We think that this effect may be migrating northward along the east and west coasts of Greenland in response to the general Holocene climatic warming (Hughes, 1986). However, the detailed history of retreat is controlled by fjord topography, especially sharp bends, bottlenecks and pinning points (Warren and Hulton, 1990). The present surface morphology of Jakobshavns Isbræ reveals that it snakes along a subglacial continuation of Jakobshavns Isfjord that extends into the Greenland ice sheet, displaying all of the above geographical constraints on stream flow (Echelmeyer and others, 1991). These constraints probably account for the stabilization of the calving front and grounding line of the floating terminus since 1964 . 




Fig. 1. Uncontrolled photo mosaic map of the Jakobshavns Isbre basin. Ice-elevation contours and map-grid tick marks are warped to fit the mosaic. Approximate scale on ice surface is $1: 600000$. Contour interval is $100 \mathrm{~m}$. Map coordinates in Figures 1-5 are UTM zone 22 northing and easting in kilometers.

The high ablation rates on the floating terminus and on ice converging on Jakobshavns Isbræ produce surface meltwater which enters crevasses and moulins to either refreeze internally or lubricate the bed, thereby sustaining the rapid flow Echelmeyer and Harrison, 1990; Echelmeyer and others, 1991, 1992), as required for the Jakobshavns effect.

\section{PHOTOGRAMMETRY}

The University of Maine carried out a project in 1985 and 1986 to obtain ice-surface elevations and summer and annual velocities for the Jakobshavns Isbræ basin by aerial photogrammetry and to produce orthophoto maps of the area. The orthophotos and elevation-contour overlays were produced as 14 sheets at 1:50000 scale.

In order to detect any differences between summer and annual velocities, two photo missions, a year apart and each conducted twice in the same summer, ideally at least 3 weeks apart, were specified. The measurements 1 year apart were designed to maximize the accuracy of velocity determination for the slower ice converging on the main ice stream, whereas the two measurements in the same summer were designed to maximize the accuracy of the velocities for the much faster ice in Jakobshavns Isbræ itself. Photography at a scale of $1: 130000$ yields ground resolution and measurement precision of about $2 \mathrm{~m}$. Positions and elevations were to be determined by analytical aerial-block triangulation for each epoch. Targeted control points spaced two to three photo-base lengths apart along the perimeter with two additional points in the interior of the block were planned. Their positions were to be determined by Doppler satellite surveys.

Mainly due to weather limitations, the photo missions were actually flown 2 weeks apart in July in both 1985 and 1986, which reduced the accuracy of the summer velocity determinations because position errors are a larger fraction of the motion over this shortened time 
interval. The actual scale of the photographs in both seasons was somewhat smaller than specified, but this did not seriously affect the precision of the measurements. More than the minimum desired number of targets were set out and usable in each season and, with one or two exceptions, the desired precision of their ground positions was attained. However, difficulties with navigation, satellite-receiver malfunctions and loss of targets from wind or burial by blowing snow resulted in less than optimal distribution of ground-control points and thus in some degradation of the block-triangulation results.

No unequivocal figures for accuracy of position determinations, and thus velocities, can be given because no check points are available. Standard deviations of ground coordinates from the aerial triangulation-block adjustment, which come from error propagation of photo and ground-control point residuals, are given in Table 1. Standard deviations of motions calculated from the position errors of Table 1 and relative errors for the three representative extremes of motion are given in Table 2 . Precision statistics are often overly optimistic, but it should also be noted that a number of points in each epoch were discarded because they were adjudged to give unreasonable motion results. It can be argued that these were probably the most poorly determined points. Thus the statistics displayed in the tables may not be an unreasonable indicator of the accuracy of the accepted results.

The number of accepted points for each epoch and the number of common points for each velocity determination are summarized in Table 3 . The four combinations for the "year" 1985-86 yielded 338, 395, 333 and 408 acceptable common points.

Table 1. Standard deviations of ground coordinates from aerial triangulation-block adjustment

\begin{tabular}{lllll}
\hline & \multicolumn{2}{c}{1.985} & \multicolumn{2}{c}{1986} \\
Coordinate & 10 July & 24 July & 7 July & 23 July \\
& & & & \\
\hline Easting (m) & 2.03 & 1.98 & 2.58 & 2.93 \\
Northing (m) & 2.36 & 2.34 & 3.28 & 3.83 \\
Elevation (m) & 2.89 & 2.77 & 3.98 & 4.12 \\
Plan position (m) & 3.1 & 3.1 & 4.2 & 4.8 \\
& & & & \\
\hline
\end{tabular}

Table 3. Number of accepted points for each epoch and number of common points for each velocity determination

\begin{tabular}{|c|c|c|c|c|}
\hline \multicolumn{5}{|c|}{ Summer 1985} \\
\hline $\begin{array}{l}\text { Accepted } \\
10 \mathrm{fuly}\end{array}$ & $\begin{array}{l}\text { Accepted } \\
24 \text { July }\end{array}$ & $\begin{array}{l}\text { Total } \\
\text { common }\end{array}$ & $\begin{array}{l}\text { Accepted } \\
\text { common }\end{array}$ & $\begin{array}{l}\% \\
\text { accepted }\end{array}$ \\
\hline 838 & 865 & 772 & 716 & 93 \\
\hline \multicolumn{5}{|c|}{ Summer 1986} \\
\hline $\begin{array}{l}\text { Accepted } \\
7 \mathrm{July}\end{array}$ & $\begin{array}{l}\text { Accepted } \\
23 \mathrm{July}\end{array}$ & $\begin{array}{l}\text { Total } \\
\text { common }\end{array}$ & $\begin{array}{l}\text { Accepted } \\
\text { common }\end{array}$ & $\begin{array}{l}\% \\
\text { accepted }\end{array}$ \\
\hline 586 & 611 & 442 & 344 & 78 \\
\hline
\end{tabular}

Within the accuracy of our measurements, we found no difference between annual and summer velocities, thereby confirming the measurements by Echelmeyer and Harrison (1990). In our further analysis of ice dynamics presented here, however, we have used only the points measured in 1985 because there are more of them and their distribution is more representative both of regional ice converging on the main ice stream and of Jakobshavns Isbræ itself than is the case for any other time interval.

Figure 2 locates the points measured on 10 July 1985 and gives the elevation for each point. Figure 3 is the icesurface-elevation contour map based on these points. Figure 4 shows velocity vectors originating at the first position of the common points from which the velocity was determined. Figure 5 is the ice-surface-speed contour map based on these velocities. The gridding and contouring were performed with the SURFACE II plotting package (Sampson, 1978).

\section{INTERPOLATION AND DERIVATIVES}

Using our photogrammetrically determined surface-ice topography and velocity measurements, we have calculated surface strain rates, surface stresses and bed topography for an area of about $100 \mathrm{~km}$ on each side.

The raw data are irregularly spaced due to their dependence on identifiable natural features. To facilitate analysis, a regular grid with a $3 \mathrm{~km}$ spacing spanning a

Table 2. Standard deviations of motions

Summer 1985

Summer 1986

6.4

Motion

m

Error

$\mathrm{m}$

$\%$

29

268

1.6
57

15

$\begin{array}{ll}7.7 & 5 \\ 29 & 1\end{array}$

$68 \quad 1$

8.7
33

305
Fastest motion
Year 198586

5.5 


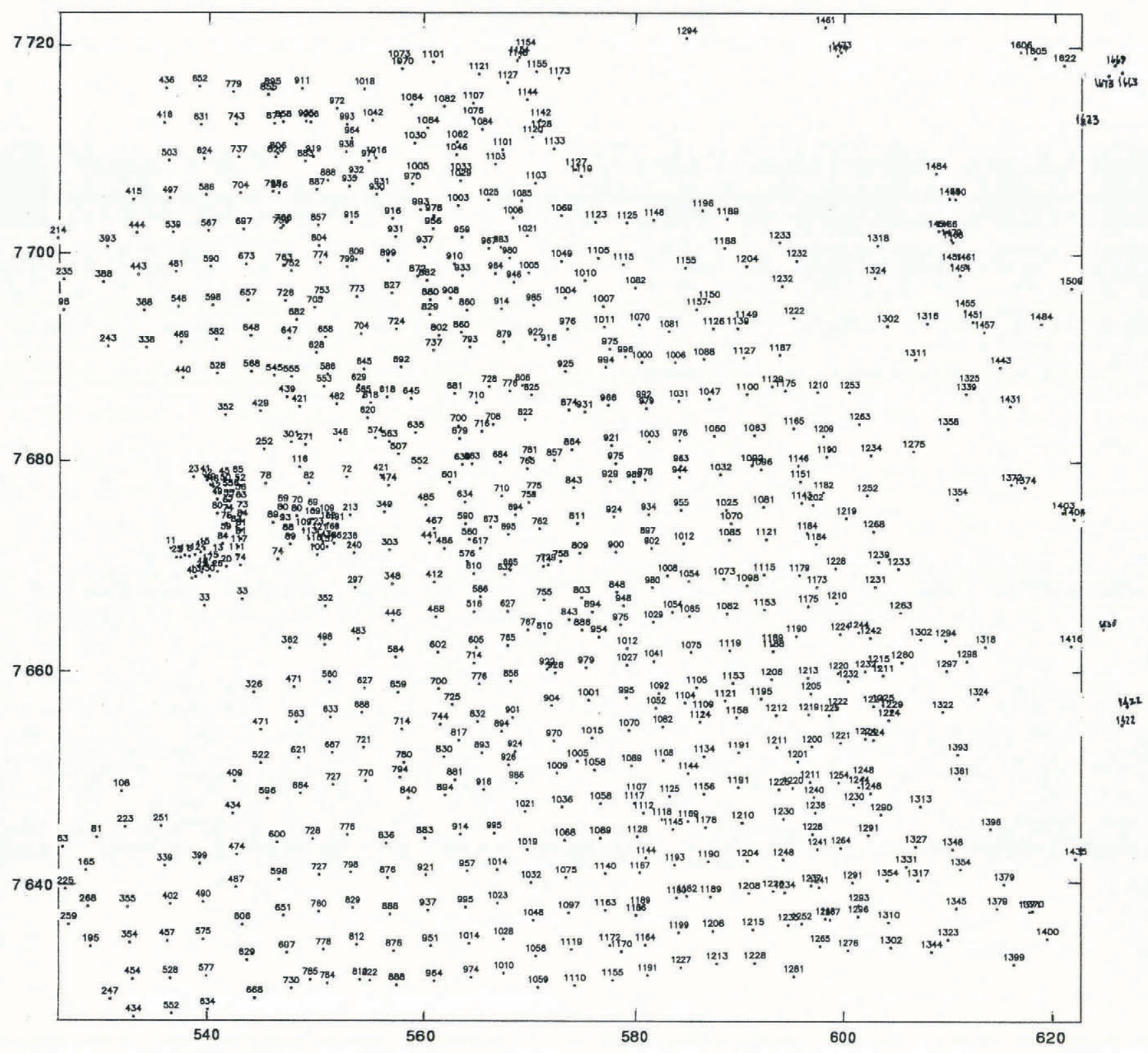

Fig. 2. Locations and elevations $(m)$ of ice-surface points measured photogrammetrically for the Jakobshavns Isbra basin on 10 July 1985 photography.

$100 \mathrm{~km}$ by $100 \mathrm{~km}$ area surrounding the Jakobshavns Isbræ outlet glacier was developed from the raw data using the SURFACE II plotting package. This spacing closely approximates the spacing of the observed natural features but provides the data in an easier-to-manipulate format.

From these elevation data we can derive surface slopes based on two-dimensional bilinear interpolation. Treating each quadrangle of gridded-surface elevations, or nodes, as an element, we may interpolate any quantity specified at the four corners by the following expression:

$$
Z(x, y)=\sum_{I=1}^{4} Z_{I} \Psi_{I}(x, y)
$$

where the $Z_{I}$ s are the values of the interpolated quantity at each of the four nodes, and the $\Psi_{I}(x, y)$ s are bilinear basis functions with the specified property that each be 1 at one node and 0 at all the other nodes. It is easy to see that spatial derivatives of nodal quantities can be obtained from Equation (1). Since only the $\Psi_{I}(x, y)$ s depend on horizontal rectilinear axes $x$ and $y$, we obtain the following expressions for the derivatives of nodal-point quantities:

$$
\begin{gathered}
\frac{\partial Z(x, y)}{\partial x}=\sum_{I=1}^{4} Z_{I} \frac{\partial \Psi_{I}(x, y)}{\partial x} \\
\frac{\partial Z(x, y)}{\partial y}=\sum_{I=1}^{4} Z_{I} \frac{\partial \Psi_{I}(x, y)}{\partial y}
\end{gathered}
$$

This treatment is not restricted to "square" quadrilaterals and can be used on any arbitrarily shaped element. The magnitude of the surface gradient, $\nabla h$, is given by

$$
|\nabla h|=\sqrt{(\partial h / \partial x)^{2}+(\partial h / \partial y)^{2}}
$$




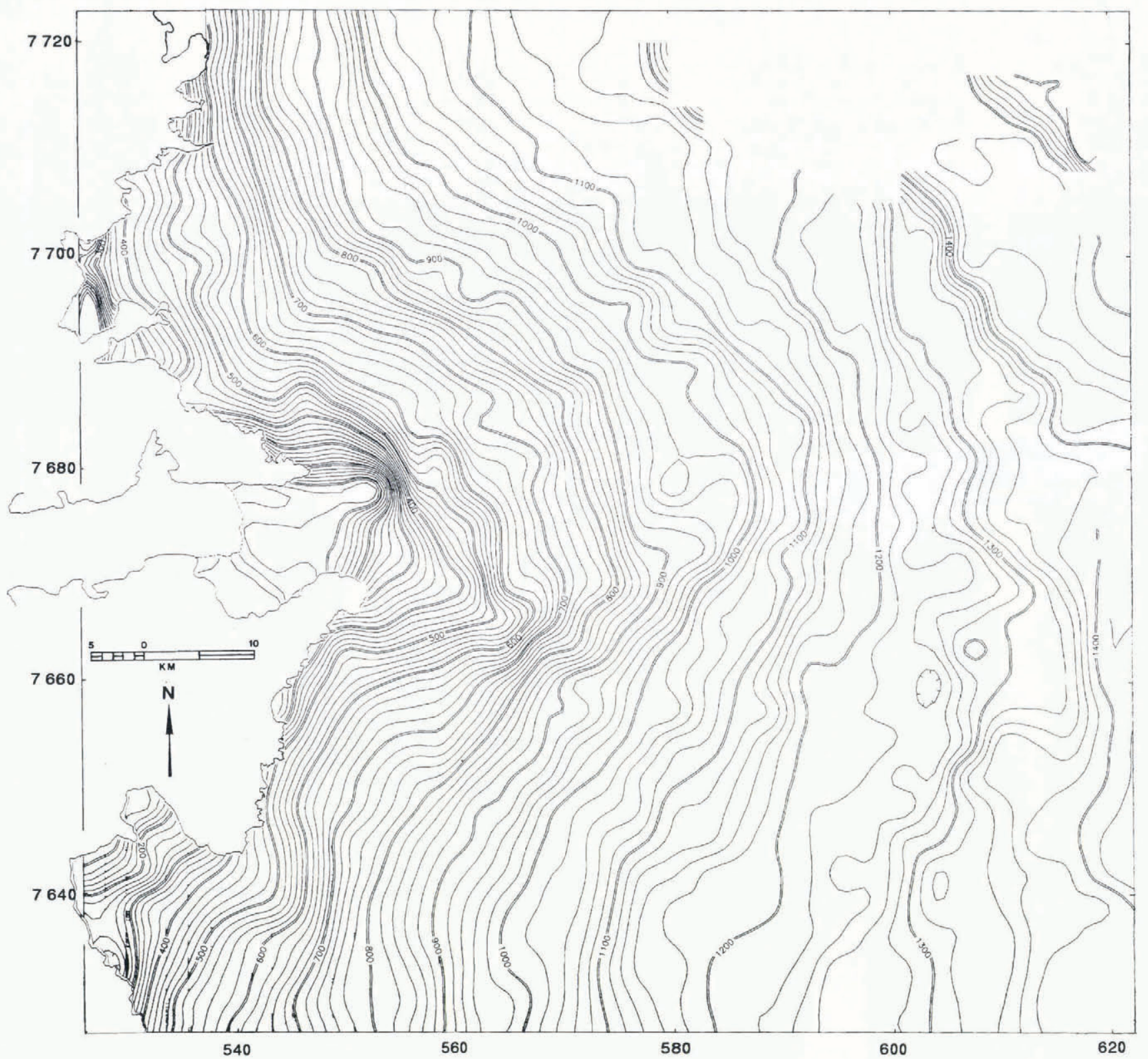

Fig. 3. Ice-surface-elevation contours derived from points in Figure 2 by gridding at $3 \mathrm{~km}$ intervals using the SURFACE II plotting package. Contour interval is $20 \mathrm{~m}$.

where $\partial h / \partial x$ and $\partial h / \partial y$ are obtained from Equations (2) and (3). Figure 6 shows a contour plot of this surface gradient obtained from the gridded data.

\section{STRAIN RATES AND STRESSES}

Using the interpolation machinery described above we can derive strain rates for each element. To make interpretation easier, we shall look at the strain rates for each element aligned longitudinally $(L)$ and transversely $(T)$ with respect to the direction of flow at the centroid of the element, rather that with respect to the $X$ and $Y$ axes. To do this we must first obtain the direction of flow at the centroid. The velocities at each node are decomposed into $X$ and $Y$ components, and using an expression similar to Equation (1) we can obtain velocity components at the centroid. These will represent the "average" or interpolated flow for the element. The angle of the $L$ axis relative to the $X$ axis is given by the following expression:

$$
\Theta=\tan ^{-1}\left(\frac{U_{Y C}}{U_{X C}}\right) .
$$

Each of the nodal-velocity values can then be transformed to the "average" flow direction by the following expressions:

$$
\begin{gathered}
U_{L}=U_{X} \cos (\Theta)+U_{Y} \sin (\Theta) \\
U_{T}=-U_{X} \sin (\Theta)+U_{Y} \cos (\Theta) .
\end{gathered}
$$

Gradients of these $L$ and $T$ components of the velocities with respect to $X$ and $Y$ can be obtained using interpolation expressions similar to Equations (2) and (3).

$$
\frac{\partial U_{L}}{\partial x}=\sum_{I=1}^{4} U_{L I} \frac{\partial \Psi_{I}}{\partial x}
$$




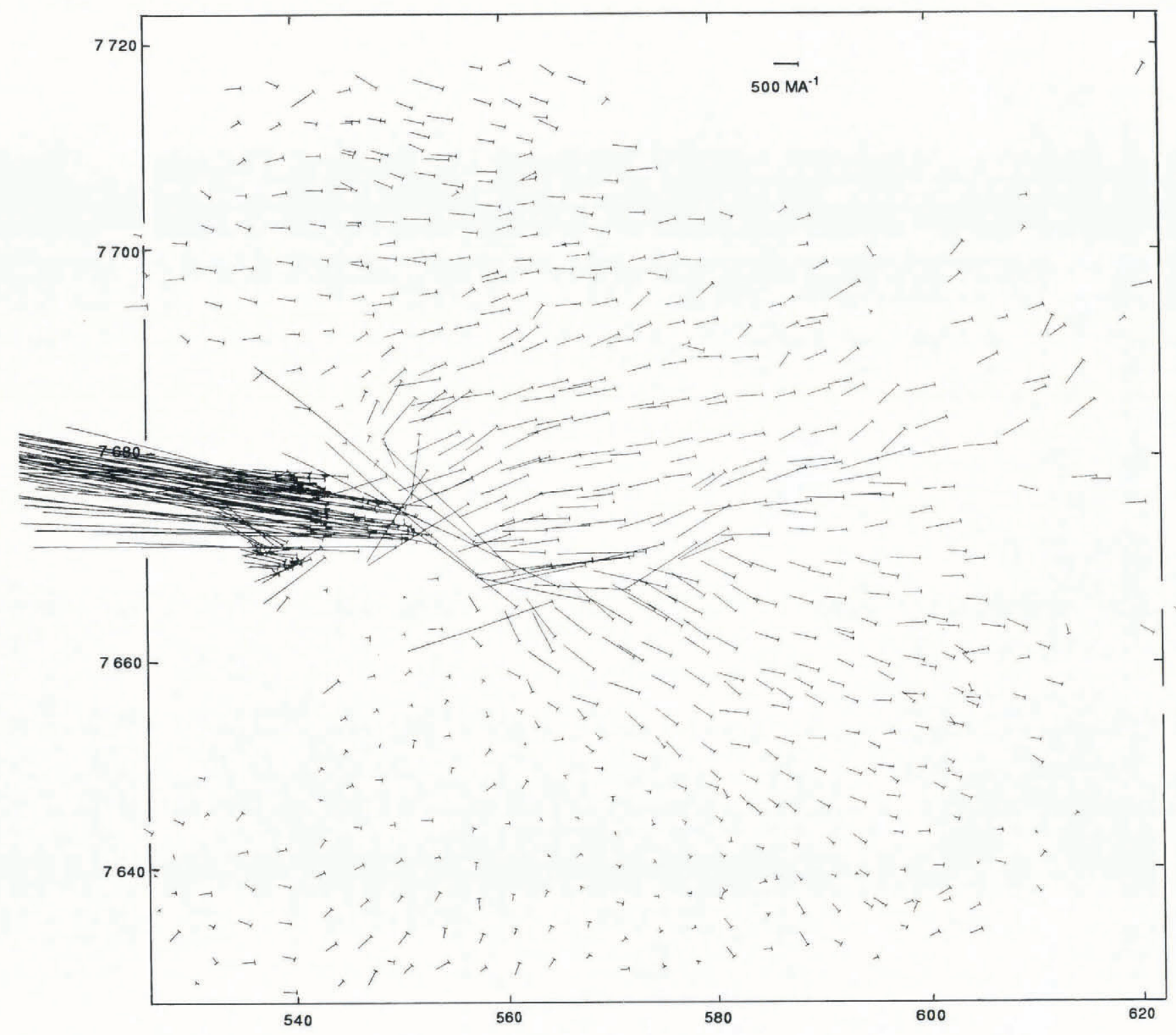

Fig. 4. Ice-velocity vectors from point positions determined photogrammetrically on 10 and 24 July 1985 photography.

$$
\begin{aligned}
& \frac{\partial U_{L}}{\partial y}=\sum_{I=1}^{4} U_{L I} \frac{\partial \Psi_{I}}{\partial y} \\
& \frac{\partial U_{T}}{\partial x}=\sum_{I=1}^{4} U_{T I} \frac{\partial \Psi_{I}}{\partial x} \\
& \frac{\partial U_{T}}{\partial y}=\sum_{I=1}^{4} U_{T I} \frac{\partial \Psi_{I}}{\partial y}
\end{aligned}
$$

Finally, gradients along the $L$ and $T$ directions can be obtained with expressions analogous to Equations (6) and (7).

$$
\begin{gathered}
\frac{\partial U_{L}}{\partial L}=\frac{\partial U_{L}}{\partial x} \cos (\Theta)+\frac{\partial U_{L}}{\partial y} \sin (\Theta) \\
\frac{\partial U_{L}}{\partial T}=-\frac{\partial U_{L}}{\partial x} \sin (\Theta)+\frac{\partial U_{L}}{\partial y} \cos (\Theta) \\
\frac{\partial U_{T}}{\partial L}=\frac{\partial U_{T}}{\partial x} \cos (\Theta)+\frac{\partial U_{T}}{\partial y} \sin (\Theta)
\end{gathered}
$$

$$
\frac{\partial U_{T}}{\partial T}=-\frac{\partial U_{T}}{\partial x} \sin (\Theta)+\frac{\partial U_{T}}{\partial y} \cos (\Theta) .
$$

Surface strain rates with respect to these local flow directions are given as usual by the following expressions and are shown in Figure $7 \mathrm{a}-\mathrm{d}$ :

$$
\begin{gathered}
\dot{\varepsilon}_{L L}=\frac{\partial U_{L}}{\partial L} \\
\dot{\varepsilon}_{T T}=\frac{\partial U_{T}}{\partial T} \\
\dot{\varepsilon}_{L T}=\frac{1}{2}\left(\frac{\partial U_{L}}{\partial T}+\frac{\partial U_{T}}{\partial L}\right) \\
\dot{\varepsilon}_{Z Z}=-\left(\dot{\varepsilon}_{L L}+\dot{\varepsilon}_{T T}\right)
\end{gathered}
$$

where Equation (19) expresses conservation of ice volume.

The surface stress field can be calculated from the surface strain rates in Equations (16)-(19) using the flow 


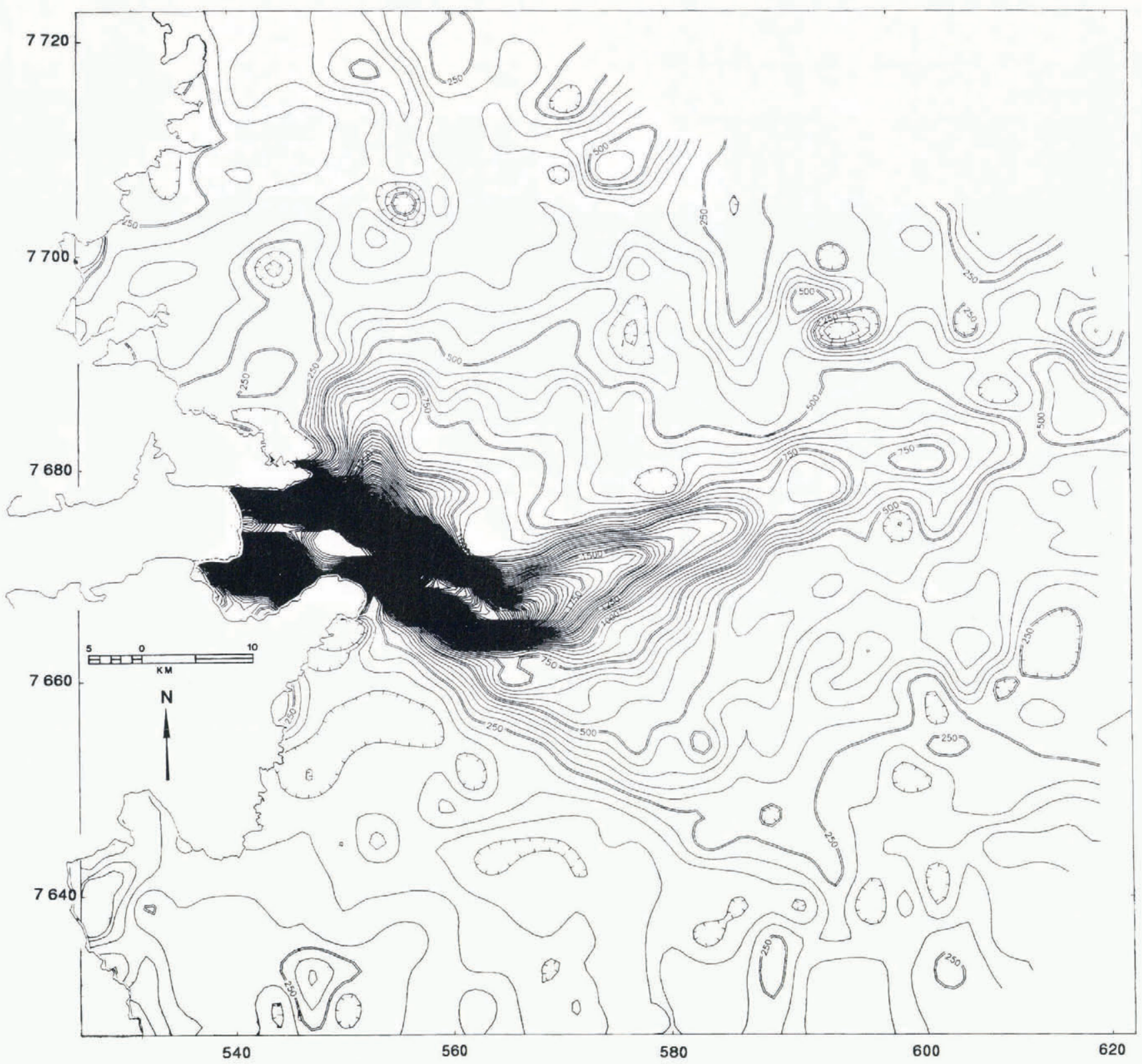

Fig. 5. Ice-speed contours derived from velocity vectors in Figure 4 by gridding at $3 \mathrm{~km}$ intervals using the SURFACE II plotting package. Contour interval is $50 \mathrm{ma}^{-1}$.

law of ice (Nye, 1952) written in terms of the effective creep rate $\dot{\varepsilon}_{C}$ and the effective creep stress $\sigma_{C}$ :

$$
\dot{\varepsilon}_{C}=\left(\sigma_{C} / A\right)^{n}
$$

and in terms of strain-rate components $\dot{\varepsilon}_{i j}$ and deviatoricstress component $\sigma_{i j}^{\prime}$ :

$$
\dot{\varepsilon}_{i j}=\left(\sigma_{C}^{n-1} / A^{n}\right) \sigma_{i j}^{\prime}
$$

where $A$ is a temperature-dependent ice-hardness parameter, $n$ is a visco-plastic parameter, and $i j$ is $L L, T T$ or $L T$.

Combining Equations (20) and (21), and solving for $\sigma_{i j}^{\prime}=\sigma_{L L}^{\prime}$ we have:

$$
\sigma_{L L}^{\prime}=\frac{A^{n} \dot{\varepsilon}_{L L}}{\sigma_{C}^{n-1}}=\frac{A^{n} \dot{\varepsilon}_{L L}}{\left(A \dot{\varepsilon}_{C}^{1 / n}\right)^{n-1}}=\frac{A \dot{\varepsilon}_{L L}}{\dot{\varepsilon}_{C}{ }^{(n-1) / n}} .
$$

By definition, with $\dot{\varepsilon}_{T Z}=\dot{\varepsilon}_{Z L}=0$ as a free-surface boundary condition, we have:

$$
\begin{gathered}
\dot{\varepsilon}_{C}=\left[\frac{1}{2}\left(\dot{\varepsilon}_{L L}{ }^{2}+\dot{\varepsilon}_{T T}{ }^{2}+\dot{\varepsilon}_{Z Z}{ }^{2}+2 \dot{\varepsilon}_{L T}{ }^{2}+2 \dot{\epsilon}_{T Z}^{2}+2 \dot{\varepsilon}_{Z L}{ }^{2}\right)\right]^{\frac{1}{2}} \\
=\left(\dot{\varepsilon}_{L L}{ }^{2}+\dot{\varepsilon}_{T T}{ }^{2}+\dot{\varepsilon}_{L L} \dot{\varepsilon}_{T T}+\dot{\varepsilon}_{L T}{ }^{2}\right)^{\frac{1}{2}} \\
=\left(1+R_{T T}+R_{T T}{ }^{2}+R_{L T}{ }^{2}\right)^{\frac{1}{2}} \dot{\varepsilon}_{L L} \\
=R_{L L} \dot{\varepsilon}_{L L}
\end{gathered}
$$

where $\dot{\varepsilon}_{Z Z}=-\left(\dot{\varepsilon}_{L L}+\dot{\varepsilon}_{T T}\right)$ for conservation of volume, and by definition:

$$
\begin{gathered}
R_{L L}=\sqrt{1+R_{T T}+R_{T T}{ }^{2}+R_{L T}{ }^{2}} \\
R_{T T}=\frac{\dot{\varepsilon}_{T T}}{\dot{\varepsilon}_{L L}}
\end{gathered}
$$




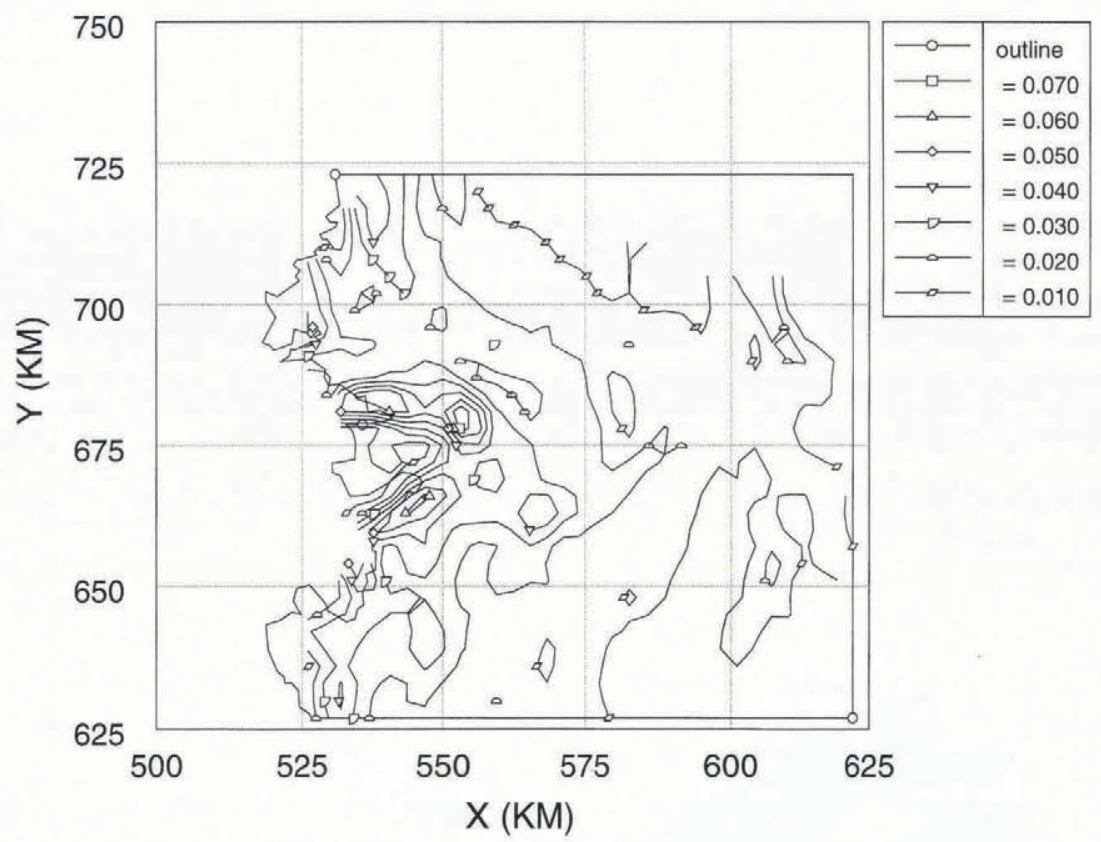

Fig. 6. Surface-elevation gradient contours derived from the gridded data in Figure 3.
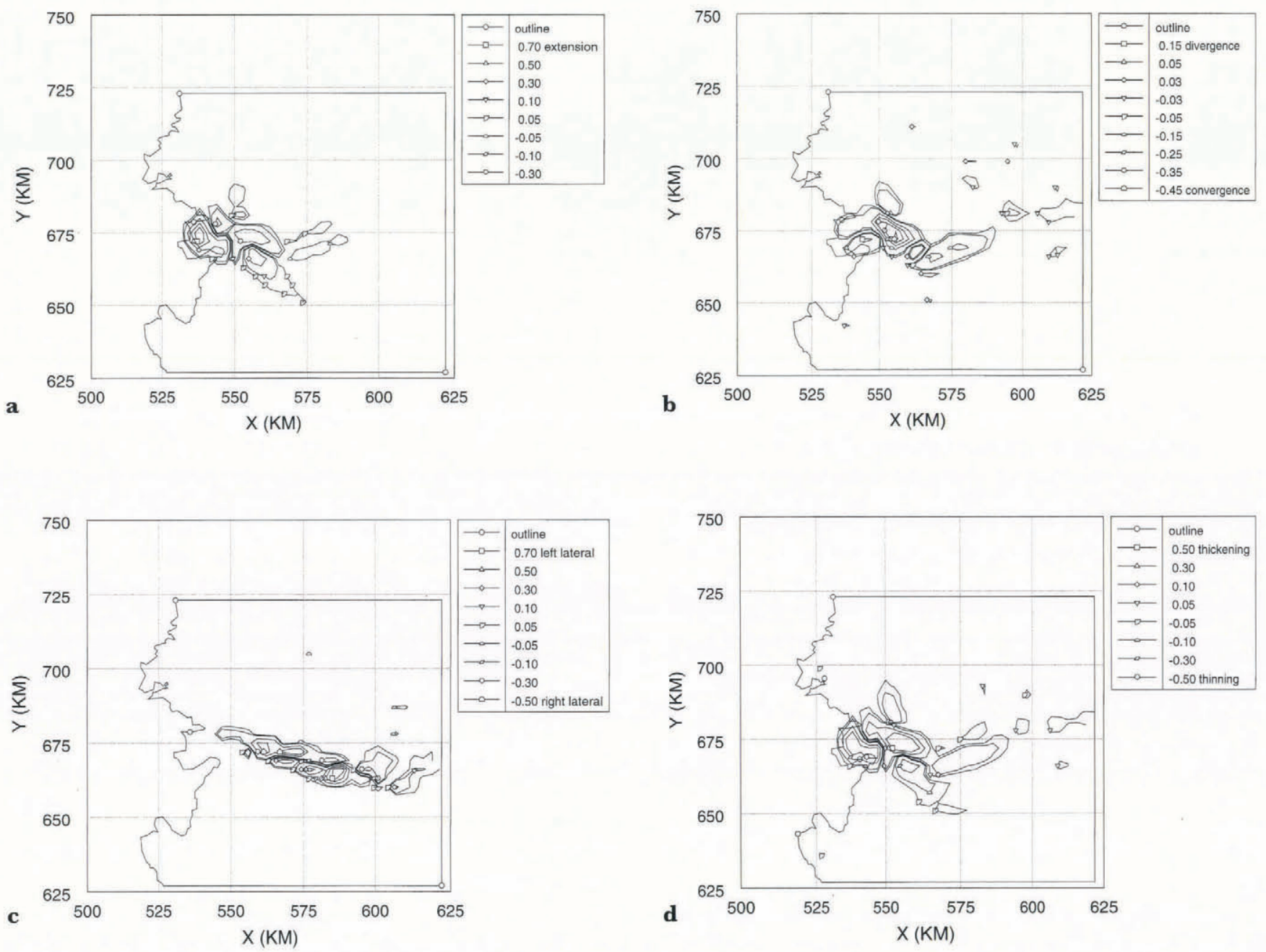

Fig. 7. a. Contours of surface longitudinal strain rate $\dot{\varepsilon}_{L L}\left(a^{-1}\right)$ along ice flow. $b$. Contours of surface transverse strain rate $\dot{\varepsilon}_{T T}\left(a^{-1}\right)$ across ice flow. $c$. Contours of surface shear strain rate $\dot{\varepsilon}_{L T}\left(a^{-1}\right)$ with respect to ice-flow direction. $d$. Contours of surface vertical strain rate $\dot{\varepsilon}_{Z Z}=-\left(\dot{\varepsilon}_{L L}+\dot{\varepsilon}_{T T}\right)\left(a^{-1}\right)$. 


$$
R_{L T}=\frac{\dot{\varepsilon}_{L T}}{\dot{\varepsilon}_{L L}} .
$$

An expression for $\sigma_{C}$ in terms of $R_{L L}$ and $\sigma_{L L}^{\prime}$ is obtained from Equations $(20)-(22)$ for $i j=L L$ :

$$
\begin{gathered}
\sigma_{C}=\frac{\sigma_{C}^{n}}{\sigma_{C}^{n-1}} \\
=\frac{A^{n} \dot{\varepsilon}_{C}}{A^{n}\left(\dot{\varepsilon}_{L L} / \sigma_{L L}^{\prime}\right)} \\
=\frac{R_{L L} \dot{\varepsilon}_{L L}}{\dot{\varepsilon}_{L L} / \sigma_{L L}^{\prime}} \\
=R_{L L} \sigma_{L L}^{\prime} .
\end{gathered}
$$

Surface stresses can now be expressed in terms of measured surface strain rates using Equation (21) with $i j$ being $L L, T T$ and $L T$, and $n=3$ for glacial ice:

$$
\begin{aligned}
& \sigma_{L L}^{\prime}=\frac{A^{3} \dot{\varepsilon}_{L L}}{\sigma_{C}^{2}} \\
& =\frac{A^{3} \dot{\varepsilon}_{L L}}{\left(A \dot{\varepsilon}_{C^{\frac{1}{3}}}\right)^{2}} \\
& =\frac{A \dot{\varepsilon}_{L L}}{\left(R_{L L} \dot{\varepsilon}_{L L}\right)^{\frac{2}{3}}} \\
& =\frac{A \dot{\varepsilon}_{L L^{\frac{1}{3}}}}{R_{L L^{\frac{2}{3}}}} \\
& \sigma_{T T}^{\prime}=\frac{A^{3} \dot{\varepsilon}_{T T}}{\sigma_{C}^{2}}=\frac{A^{3} \dot{\varepsilon}_{T T}}{R_{L L}{ }^{2} \sigma_{L L}{ }^{2}}=\frac{A \dot{\varepsilon}_{T T^{\frac{1}{3}}}}{R_{L L^{\frac{2}{3}}}} \\
& \sigma_{L T}^{\prime}=\frac{A^{3} \dot{\varepsilon}_{L T}}{\sigma_{C}^{2}}=\frac{A^{3} \dot{\varepsilon}_{L T}}{R_{L L}{ }^{2} \sigma_{L L}{ }^{2}}=\frac{A \dot{\varepsilon}_{L T^{\frac{1}{3}}}}{R_{L L^{\frac{2}{3}}}}
\end{aligned}
$$

and $A$ can be calculated from the mean annual icesurface temperature (Glen, 1955). Stresses with respect to the $L$ and $T$ directions obtained from Equations (28)(30) are shown in Figure 8a-c.

\section{DERIVED BED TOPUGRAPHY}

With the extensive photogrammetric measurements on Jakobshavn Isbræ and its catchment area, we are able to treat the measured surface elevations and velocities as known quantities, and derive the ice thickness necessary to produce this flow within the constraints of a particular value for the flow constant, the sliding constant and the fraction of the velocity which is due to sliding.

The column-averaged flow velocity obtained from Equation (21) for the component of velocity due to internal deformation of the ice is given by the following expression:
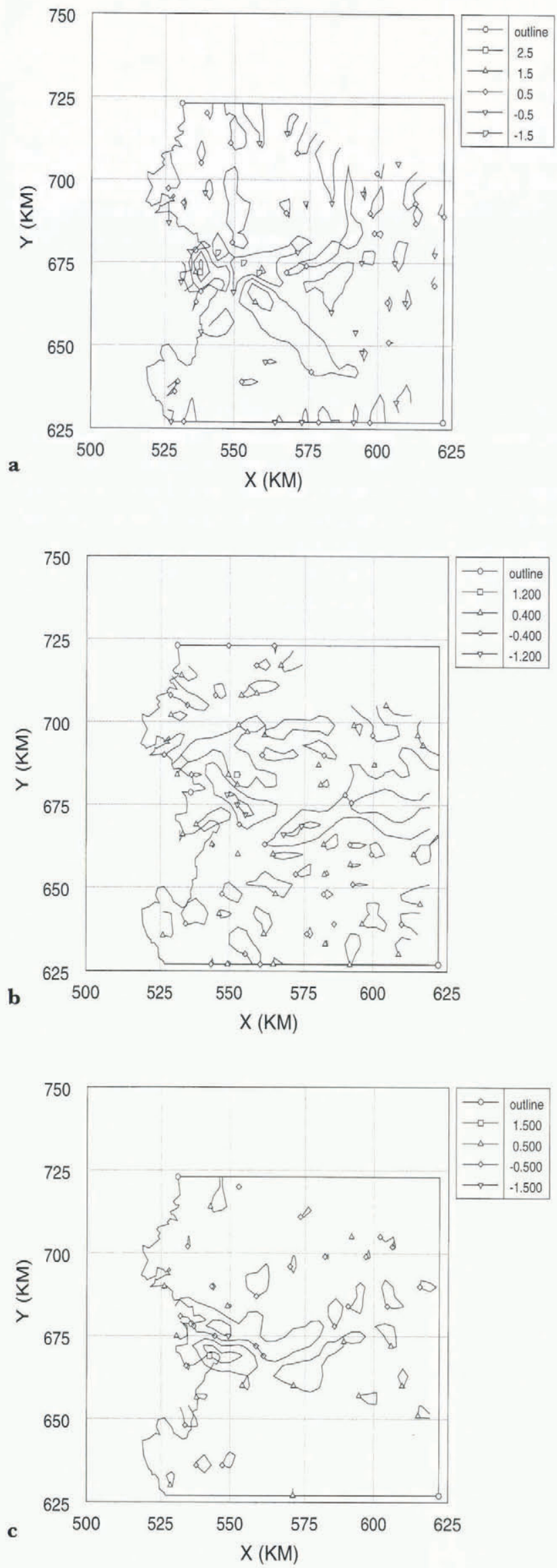

Fig. 8. a. Contours of surface longitudinal deviatoric stress $\sigma_{L L}^{\prime}$ (bar) along ice flow. $b$. Contours of surface transverse deviatoric stress $\sigma_{T T}^{\prime}$ (bar) across ice flow. $c$. Contours of surface shear deviatoric stress $\sigma_{L T}^{\prime}$ (bar) with respect to ice-flow direction. 


$$
U_{F}=\frac{2}{n+2}\left[\frac{\rho g|\nabla h|}{A}\right]^{n} H^{n+1}
$$

where $A$ is the column-averaged flow constant for an ice column of thickness $H$ and of surface height $h$ above sea level, $\rho$ is ice density and $g$ is the acceleration of gravity.

The sliding law used here is a general relationship for beds at the melting point developed by Weertman (1957, 1964) and given by the following expression:

$$
U_{S}=\left[\frac{\rho g|\nabla h|}{B}\right]^{m} H^{m}
$$

where parameter $B$ includes bed roughness and $m$ is a visco-plastic parameter for sliding temperate basal ice. We use this sliding law because it applies to rough bedrock, not to a deformable till. The deglaciated area beyond the ice margin is nearly all exposed bedrock, with little or no till cover (see Fig. 1).

The column-averaged ice velocity for a combination of these two modes of motion is

$$
U=f U_{S}+(1-f) U_{F}
$$

where $f$ is the fraction of velocity due to sliding. What $f$ does is reduce the vertical shear gradient in ice as basal sliding replaces internal shear in contributing to total ice velocity. Without $f$, column-averaged values of $A$ and constant $B$ in Equations (31) and (32) would have to be replaced with values of $A$ and $B$ that depended on what fraction of the bed allows basal sliding. There is no physical reason for $A$ and $B$ to depend on this fraction, although $f$ itself most likely depends on the basal temperature, which is not calculated in this model. Others have attempted to calculate basal temperatures for fast-flowing ice by explicitly including horizontal advection (Funk and others, 1993), but accurate calculation of basal temperatures will probably require a full three-dimensional temperature solution.

Combining Equations (31), (32) and (33), one obtains the following expression relating the measured velocity fields and surface elevations to the unknown ice thicknesses:

$$
U=f\left[\frac{\rho g|\nabla h|}{B}\right]^{2} H^{2}+(1-f) \frac{2}{5}\left[\frac{\rho g|\nabla h|}{A}\right]^{3} H^{4}
$$

where the flow and sliding exponents, $n$ and $m$ have been replaced with their traditional values, 3 and 2, and $A$ and $B$ are taken to be $3.0 \mathrm{barm} \mathrm{a}^{-\frac{1}{3}}$ and $0.03 \mathrm{barma}^{-\frac{1}{2}}$, respectively. This presents a fourth-degree equation in $H$, the ice thickness, which can be solved by ordinary numerical methods. Strictly speaking, both $U$ and $\nabla h$ are themselves vector quantities, so that two equations relating the $X$ and $Y$ components of the velocity with the $X$ and $Y$ surface gradients are available. We have chosen to relate the magnitude of the velocity to the magnitude of the surface gradient to avoid ambiguities due to inaccuracies in the measured data. When a thickness has been obtained, the bedrock elevation can be obtained by simply subtracting the thickness from the measured surface elevation, (see Fig. 9).

The accuracy of this calculated bedrock surface is dependent upon the accuracy of the original measured surface-elevation and velocity data, as well as upon the values chosen for the various constants, $A$, the flow-law parameter, $B$, the sliding-law parameter, and $f$, the percentage of the velocity due to sliding. Bahr and others (1992) have shown that small errors in measured surface strain rates alone lead to large errors in calculated ice thicknesses. Their prediction can be tested by comparing our calculated ice thicknesses with those measured by K. Echelmeyer (unpublished information). To understand the sensitivity of the calculated bed's dependence on these inputs, we varied the data and parameters systematically and observed the change in the average thickness, from which the bed is directly calculated. We observed that the

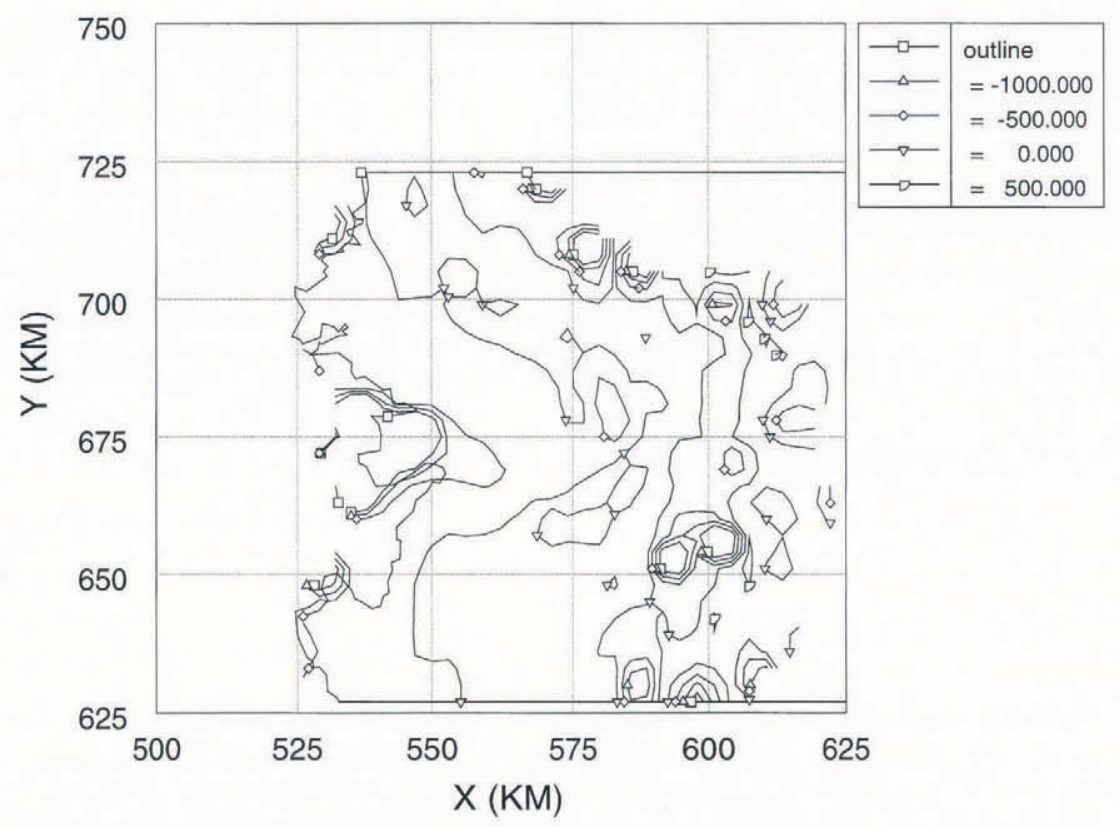

Fig. 9. Calculated bedrock-elevation contours $(m)$. 
greatest variation in average thickness occurred for variation of the measured surface height, a decrease of $14.8 \mathrm{~m}$ for each $1 \%$ overestimate of the surface height. The next strongest was the sliding constant, $B$, for which an increase of $8.9 \mathrm{~m}$ for each $1 \%$ overestimate of the constant was observed. An overestimate of the measured velocity by $1 \%$ resulted in an increase in thickness of $6.4 \mathrm{~m}$. An overestimate of the flow constant by $1 \%$ resulted in an increase in thickness of $5.8 \mathrm{~m}$. Least sensitive was the dependence of the thickness on the choice of the fraction of the velocity due to sliding, which indicated a decrease in the surface elevation of only $4.2 \mathrm{~m}$ for each $1 \%$ overestimate in the fraction. Unfortunately this is the least well-constrained of the input parameters, and an overall variation for the entire range of allowed fractions ( 0 for no sliding, 1 for all sliding) is over $1600 \mathrm{~m}$. These results are summarized in Table 4.

Table 4. Change in average thickness for $1 \%$ overestimate

$\begin{array}{cc}\text { Measured data } & \text { Increase or decrease } \\ \text { or parameter } & \text { in thickness }\end{array}$

$\mathrm{m}$

$\begin{array}{lr}\text { Elevation } & -14.8 \\ \text { Sliding constant } & 8.9 \\ \text { Velocity } & 6.4 \\ \text { Flow constant } & 5.8 \\ \text { Fraction } & -4.2\end{array}$

Assuming an error in all estimated parameters and measured data of $10 \%$, the thickness would be in error by about 400 out of $1600 \mathrm{~m}$, or about $25 \%$. It is clear that this derived bed is an estimate of the underlying terrain, and not a rigorous measurement.

This bedrock surface is used as input to the map-plane finite-element model, from which a calculated surface is obtained. The finite-element model is a column-averaged continuity-equation solver described in detail elsewhere (Fastook and Prentice, 1994). Briefly this model solves a two-dimensional continuity equation

$$
\nabla \cdot \sigma(x, y)=\dot{a}(x, y)-\frac{\partial h}{\partial t}
$$

where $\sigma$ is the flux through a point, $\dot{a}$ is the net mass balance at a point, and $h$ is the ice-surface elevation. A differential equation is obtained by expressing the flux as

$$
\sigma(x, y)=-k(x, y) \nabla h(x, y)=U H
$$

where $U$ is the column-averaged velocity of Equation (34) and $H$ is the ice thickness. The non-linear constant $k(x, y)$ incorporates the physics of the flow and sliding laws into the problem, since its form depends on the form of the flow and sliding laws. Different treatments of the flow and sliding processes change the form of $k(x, y)$ but do not affect the method by which the problem is solved. The resulting non-linear differential equation

$$
\nabla \cdot(-k(x, y) \nabla h)=\dot{a}(x, y)-\frac{\partial h}{\partial t}
$$

can be solved by an iterative Galerkin finite-element formulation (Becker and others, 1981).

In this model the fraction of the velocity due to sliding has been used as an adjustable parameter to obtain a good fit to the measured surface. This is done in an iterative fashion where the surface at each node is compared with the measured surface, and a correction to the fitting parameter applied in such a way as to improve the fit. After approximately 1000 iterations the distribution-of-sliding fraction shown in Figure 10 is

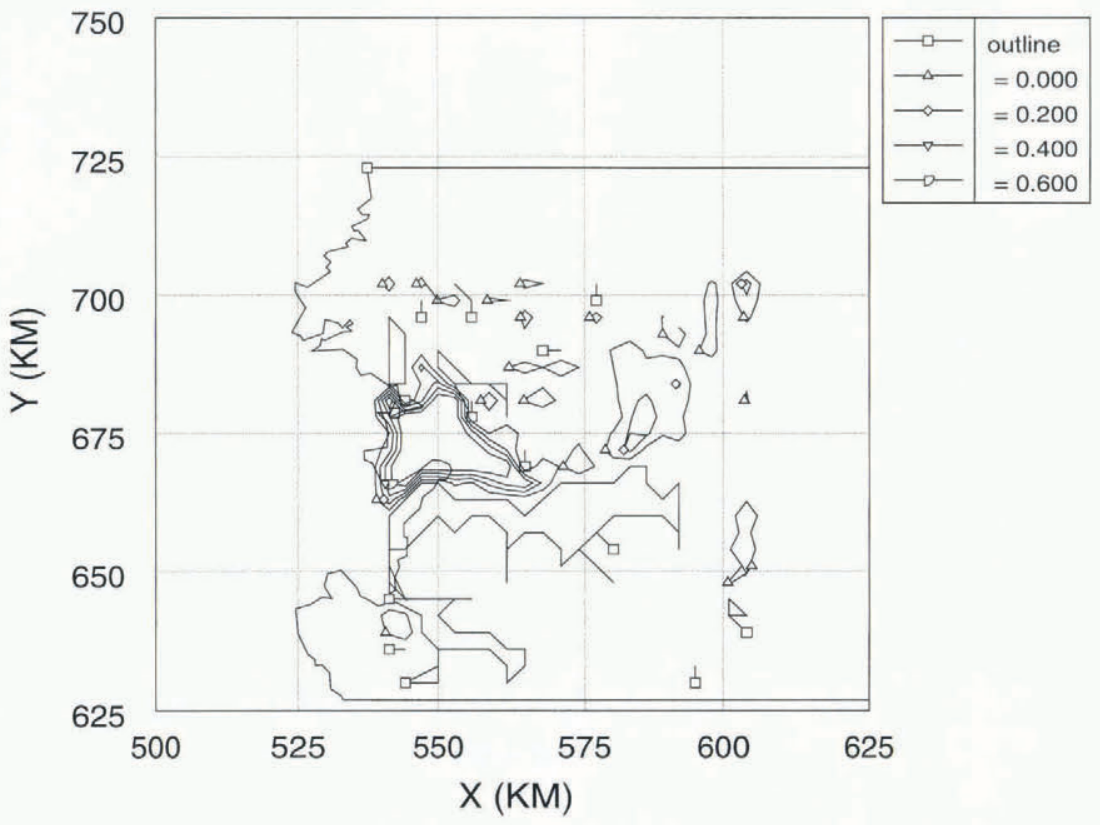

Fig. 10. Fraction of total ice velocity due to basal sliding. 
obtained. Note the predominance of sheet flow over most of the region, with sliding-dominated flow occurring just before the ice stream becomes afloat. Minor branches of enhanced-sliding regions extend out along the primary branch of the ice stream (flow from the east), although there is no evidence in the fitted fraction for the secondary branches of the ice stream (flow from the north and from the southeast).

One must certainly note that the procedure for estimating the bed topography itself uses the fraction $f$ and that this fraction is then fitted using the finite-element model. Attempts to iterate this process were unsuccessful. Instead a small fraction $(0.10)$ is used in the bedgeneration process, and the finite-element model can be considered to be a means of refining the detail in the spatial distribution of sliding.

The surface calculated from this sliding-fraction distribution is shown in Figure 11, and the agreement with the measured surface is quite good. Some of the finer details of the surface are lost in this calculation, but this is to be expected considering the limitations of the columnaveraged model.

In addition to calculating the surface, the mapplane finite-element model also provides velocities, which are shown in Figure 12. In general there is quite good agreement with the general pattern derived from measured velocities seen in Figures 4 and 5. The three branches of the ice stream are still evident, although the separation is not as clear. There are minor discrepancies north of the ice stream where the measured west-to-east flow is not duplicated in the calculated velocities, and the complex flow pattern measured in the southwest quadrant is also not manifest in the calculated velocities.

This paper demonstrates the possibility of deriving an approximation of the bedrock topography underlying an area with sufficient repeated photogrammetric coverage to obtain surface velocities and elevations. This technique can be used when radar flight-line

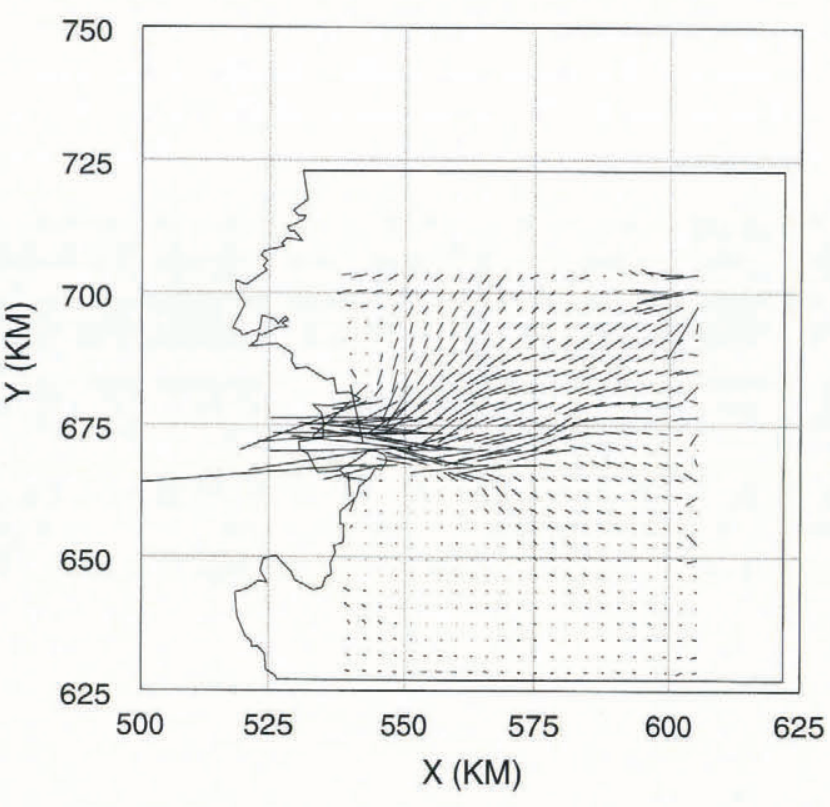

Fig. 12. Calculated surface velocity vectors $\left(\mathrm{ma}^{-1}\right)$ for comparison with measured vectors in Figure 4.

coverage is insufficient or unavailable. While the steps in this exercise are somewhat circular (we have used a column-averaged velocity to obtain the thickness, which we then modeled with a column-average model), we are provided with initial conditions for further work on the catchment area, which can include modeling of the behavior of the grounding line in response to changing climatic conditions. In a sense, what we have done is "tune" our model, in a manner analogous to the "tuning" that is done on global circulation models. Further tests of the model's behavior in the time domain will help us to refine and validate these assumptions.

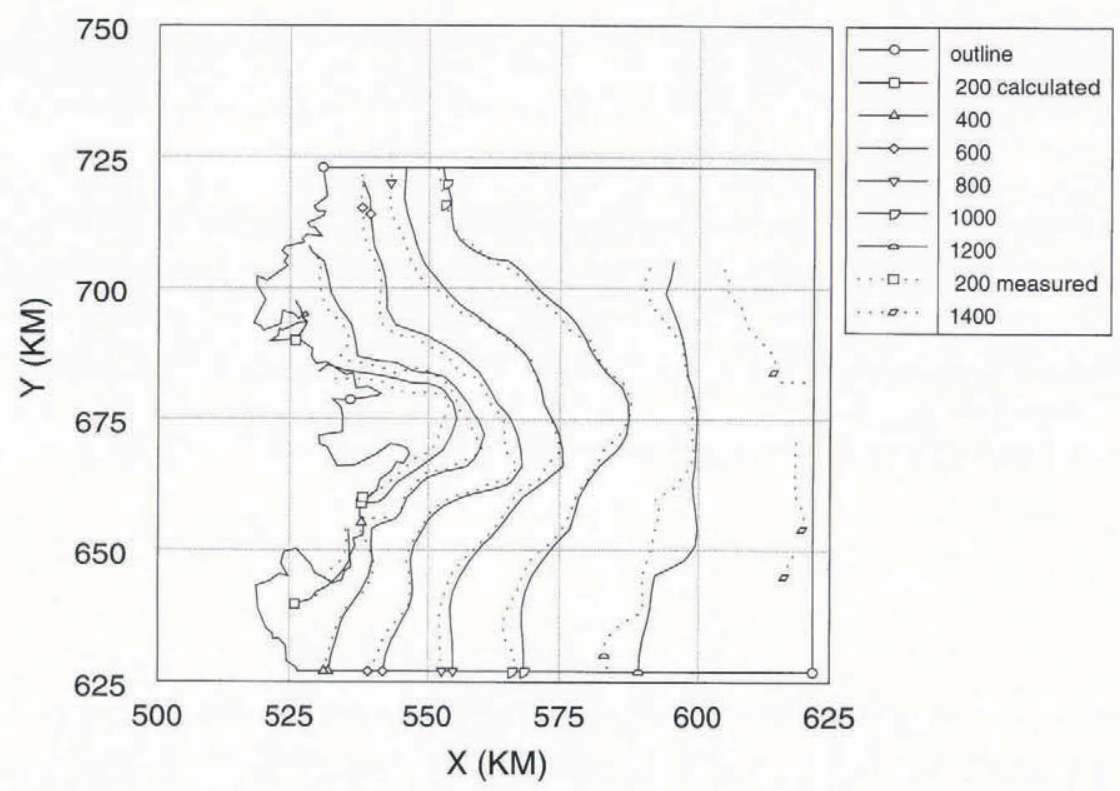

Fig. 11. Calculated surface-elevation contours, indicated by solid lines, and measured surface elevation contours, indicated by dashed lines. 


\section{ACKNOWLEDGEMENTS}

We wish to acknowledge the support of the U.S. National Science Foundation, which has generously supported this work through numerous grants, in particular NSF RII8922105, "EPSCOR Abrupt Climate Change", which provided the hardware on which much of this work was performed, and DPP-9120532, "A study of calving dynamics for Jakobshavns Isbræ". Copies of these and various other graphical and digital results from the photogrammetry can be made available to interested investigators for the cost of reproduction or transmission.

\section{REFERENGES}

Bahr, D., W. T. Pfeffer and M. F. Meier. 1992. Stress perturbations from compressional flow: the propagation of calculation errors from the surface to the bed of a glacier. [Abstract.] EOS, 73 (43), Fall Meeting Supplement, 159.

Becker, E. B., G. F. Carey and J. T. Oden. 1981. Finite elements. An introduction. Englewood Cliffs, NJ, Prentice-Hall.

Bindschadler, R. A. 1984. Jakobshavns glacier drainage basin: a balance assessment. 7. Geophys. Res., 89 (C2), 20662072.

Carbonnell, M. and A. Bauer. 1968. Exploitation des couvertures photographiques aériennes répétées du front des glaciers vêlant dans Disko Bugt en Umanak Fjord, juin-juillet, 1964. Medd. Gronl., $173(5)$.
Echelmeyer, K. and W. D. Harrison. 1990. Jakobshavns Isbræ, West Greenland: seasonal variations in velocity or lack thereof. $f$. Glaciol., 36(122), 82-88.

Echelmeyer, K., T.S. Clarke and W.D. Harrison. 1991. Surficial glaciology of Jakobshavns Isbræ, West Greenland: Part I. Surface morphology. 7. Glaciol., 37(127), 368-382.

Echelmeyer, K., W. D. Harrison, T. S. Clarke and C. Benson. 1992. Surficial glaciology of Jakobshavns Isbre, West Greenland: Part II. Ablation, accumulation, and temperature. f. Glaciol., 38(128), 169-181.

Fastook, J.L. and M. Prentice. 1994. A finite-element model of Antarctica: sensitivity test for meteorological mass-balance relationship. 7. Glaciol., 40 (134), 167-175.

Funk, M. M., K. Echelmeyer and A. Iken. 1993. Mechanism of fast flow in Jakobshavns Isbrae, Greenland. Part II. Modeling of englacial temperatures. Presented at Workshop on the Calving Rate of West Greenland Glaciers in Response to Climate Change, Danish Polar Center, Copenhagen, Denmark, 1315 September, 1993.

Glen, J. W. 1955. The creep of polycrystalline ice. Proc. R. Soc. London, Ser. A, 228 (1175), 519-538.

Hughes, T. 1986. The Jakobshavns effect. Geophys. Res. Lett., 13 (1), 46-48.

Nye, J.F. 1952. The mechanics of glacier flow. J. Glaciol., 2(12), 8293.

Pelto, M.S., T.J. Hughes and H. H. Brecher. 1989. Equilibrium state of Jakobshavns Isbræ, West Greenland. Ann. Glaciol., 12, 127-131.

Sampson, R. J. 1978. Surface II graphics system. Revision one. Lawrence, KS, Kansas Geological Survey.

Warren, C. R. and N.R.J. Hulton. 1990. Topographic and glaciological controls on Holocene ice-sheet margin dynamics, central West Greenland. Ann. Glaciol., 14, 307-310.

Weertman, J. 1957. On the sliding of glaciers. F. Glaciol., 3 (21), 33 38.

Weertman, J. 1964. The theory of glacier sliding. J. Glaciol., 5(39), 287303.

MS received 16 March 1994 and in revised form 28 June 1994 